\title{
Phylloporia nouraguensis, an Undescribed Species on Myrtaceae from French Guiana
}

Article in Cryptogamie Mycologie · March 2013

DOI: 10.7872/crym.v34.iss1.2013.15

\section{CITATIONS}

17

4 authors:

Cony Decock

Université Catholique de Louvain - UCLouvain

211 PUBLICATIONS 2,385 CITATIONS

SEE PROFILE

Gerardo Robledo

IMBIV, CONICET, UNC

74 PUBLICATIONS 542 CITATIONS

SEE PROFILE
Mario Amalfi

Botanic Garden Meise

22 PUBLICATIONS 276 CITATIONS

SEE PROFILE

Gabriel Castillo

University of Liège

21 PUBLICATIONS 381 CITATIONS

SEE PROFILE

Some of the authors of this publication are also working on these related projects:

tropical Basidiomycetes metabolites View project

Edible Fungi of Katanga (DR Congo) View project 


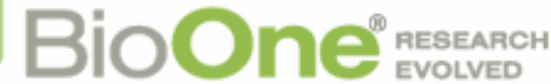

\section{Phylloporia nouraguensis, an Undescribed Species on Myrtaceae from French Guiana}

Author(s): Cony Decock, Mario Amalfi , Gerardo Robledo \& Gabriel Castillo

Source: Cryptogamie, Mycologie, 34(1):15-27. 2013.

Published By: Association des Amis des Cryptogames

DOI: http://dx.doi.org/10.7872/crym.v34.iss1.2013.15

URL: http://www.bioone.org/doi/full/10.7872/crym.v34.iss1.2013.15

BioOne (www.bioone.org) is a nonprofit, online aggregation of core research in the biological, ecological, and environmental sciences. BioOne provides a sustainable online platform for over 170 journals and books published by nonprofit societies, associations, museums, institutions, and presses.

Your use of this PDF, the BioOne Web site, and all posted and associated content indicates your acceptance of BioOne's Terms of Use, available at www.bioone.org/page/ terms_of use.

Usage of BioOne content is strictly limited to personal, educational, and non-commercial use. Commercial inquiries or rights and permissions requests should be directed to the individual publisher as copyright holder. 


\title{
Phylloporia nouraguensis, an undescribed species on Myrtaceae from French Guiana
}

\author{
Cony DECOCK ${ }^{a^{*}}$, Mario AMALFI ${ }^{a}$, Gerardo ROBLEDO \\ \& Gabriel CASTILLO ${ }^{c}$
}

${ }^{a}$ Mycothèque de l'Université catholique de Louvain (MUCL, BCCM ${ }^{T M}$ ), Earth and Life Institute - Microbiology (ELIM), Université catholique de Louvain,

Croix du Sud 2 bte L7.05.06, B-1348 Louvain-la-Neuve, Belgium.
${ }^{b}$ Instituto Multidisciplinario de Biología Vegetal, Universidad Nacional de Córdoba, C.C. 495, 5000 Córdoba, Argentina.

${ }^{c}$ Département de Biologie, Ecologie et Evolution \& Service Collectif des Enseignements de Biologie, Université de Liège, 4020 Liège, Belgique.

\begin{abstract}
Phylloporia nouraguensis sp. nov. is described on the basis of several collections made in French Guiana. The species was found growing on living (or occasionally dead), small apical twigs of a species of Myrcia (Myrtaceae), in the so-called "low forest" covering the upper slopes of the Nouragues inselberg.
\end{abstract}

Hymenochaetales / LSU / Mesoamerica / Phylogeny

\section{INTRODUCTION}

During a survey of Phylloporia in the Neotropical areas (Valenzuela et al. 2011), a species morphologically and ecologically well characterized was collected repeatedly in the so-called "low forest" (Larpin 2001) covering the upper slopes of a granitic inselberg in French Guiana. The species was found producing tiny basidiomata on the apices of twigs of a local bushy Myrtaceae (Myrcia sp., perhaps M. guianensis).

It could not be satisfactorily accommodated in any of the known species, however (Cui et al. 2010, Valenzuela et al. 2011, Zhou and Dai 2012). Phylogenetic inferences, based on partial nuc-LSU DNA sequence, also resolved this species as a monophyletic, terminal clade, distinct from all the other named or unnamed species clades known to date (Valenzuela et al. 2011, Zhou \& Dai 2012).

On this basis, along with considering also its ecological specificities, we concluded that it represents an undescribed species. It described and illustrated below as Phylloporia nouraguensis.

\footnotetext{
* Corresponding author
} 


\section{MATERIALS AND METHODS}

Collection localities. - Material from French Guiana was collected in the so-called "low forest" (Larpin 2001) covering the upper slopes of the Nouragues Inselberg (approx. $04^{\circ} 05^{\prime} \mathrm{N}-52^{\circ} 40.6^{\prime} \mathrm{W}$, elev. approx. $150 \mathrm{~m}$ ), a granitic outgrowth culminating at about $400 \mathrm{~m}$. The local plant community, botanically dominated by Myrtaceae, in terms of relative diversity and abundance, is described by Larpin (2001).

Material. - Herbarium specimens of the new taxon are preserved at MUCL with a duplicate deposited at NY (herbarium acronyms are according to Thiers, continuously updated).

Morphology and anatomy. - Morphological examinations were conducted using protocols outlined by Valenzuela et al. (2011). Colors are described according to Kornerup \& Wanscher (1981). Section were carefully dissected under a stereomicroscope in warm $\left(40^{\circ} \mathrm{C}\right) \mathrm{NaOH} 3 \%$ solution, and later examined in $\mathrm{NaOH} 3 \%$ solution at room temperature. Sections were also examined in Melzer's reagent and lactic acid cotton blue. All the microscopic measurements were done in Melzer's reagent. In presenting the size range of several microscopic elements, $5 \%$ of the measurements at each end of the range are given in parentheses, when relevant. In the text, the following abbreviations are used: ave $=$ arithmetic mean, $\mathrm{Q}=$ the ratio of length/width of basidiospores, and ave $_{\mathrm{R}}=$ arithmetic mean of the ratio $\mathrm{Q}$.

Sequencing. - DNA extraction, amplification, and sequencing of the nuclear ribosomal 5' end of the LSU are as described in Decock et al. (2007). The primers LROR and LR5 were used for PCR amplifications. Successful PCR reactions resulted in a single band observed on an $0.8 \%$ agarose gel, corresponding to approximately $900 \mathrm{bp}$. Sequencing reactions were performed using CEQ DTCS Quick Start $\mathrm{Kit}^{\circledR}$ (Beckman Coulter), according to the manufacturer's recommendations, with the primers LROR, LR3, LR3R, LR5 (http://biology.duke.edu/fungi/mycolab/primers.htm).

Phylogenetic analysis. - Sixty-five specimens and cultures representing 41 species or potential species clades were included in the phylogenetic analysis. Materials and sequences used in this study are listed in Table I.

Nucleotide sequences were automatically aligned with Clustal X 2.0.11 (Thompson et al. 1997). Potentially ambiguously aligned segments were detected using Gblocks v0.91b (Castresana 2000; http://molevol.cmima.csic.es/castresana/ Gblocks.html) with the settings "allow smaller final blocks" and "allow gaps within blocks". The alignment was then manually adjusted as necessary with the text editor in PAUP* 4.0b10. Inonotus micantissimus, MUCL52413, a species of the Inonotus clade sensu Wagner and Fischer, was designated as outgroup (Larsson et al. 2006).

Phylogenetic analyses were performed using maximum parsimony (MP) as implemented in PAUP* 4.0b10 (Swofford 2003), Bayesian inference (BI) as implemented in MrBayes v3.1.2 (Huelsenbeck and Ronquist 2001), and Maximum likelihood (ML) searches were conducted with RAxML 7.0.4 (Stamatakis 2006). The general time reversible model (GTR), using proportion of invariant sites and distribution of rates at variable sites modeled on a discrete gamma distribution with four rate classes, was estimated as the best-fit likelihood model of evolution for Bayesian inference and Maximum likelihood, using the AIC (Akaike Information Criterion) as implemented in Modeltest 3.7 (Posada \& Crandall 1998). 
Phylloporia nouraguensis, an undescribed species on Myrtaceae from French Guiana 17

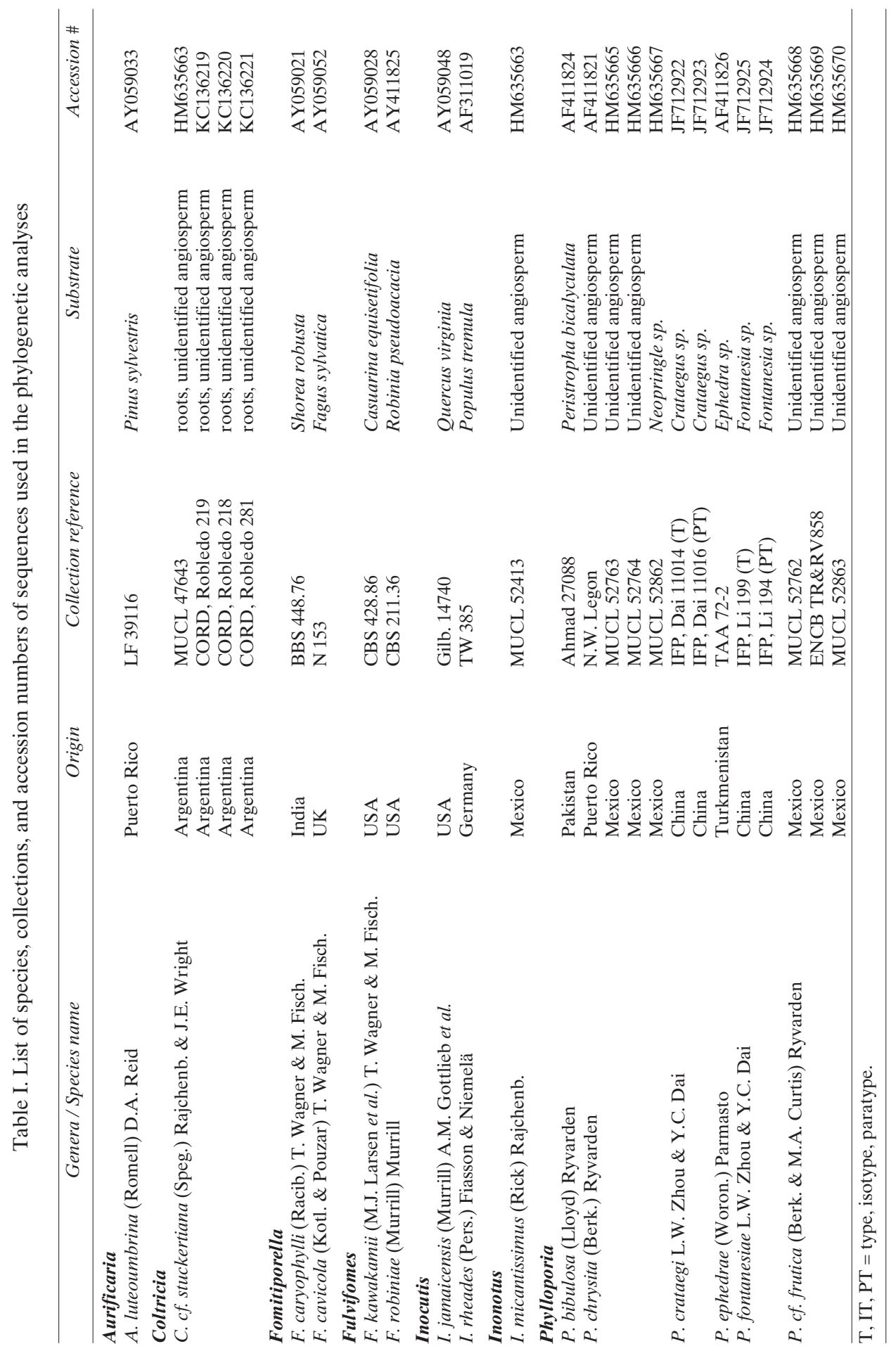




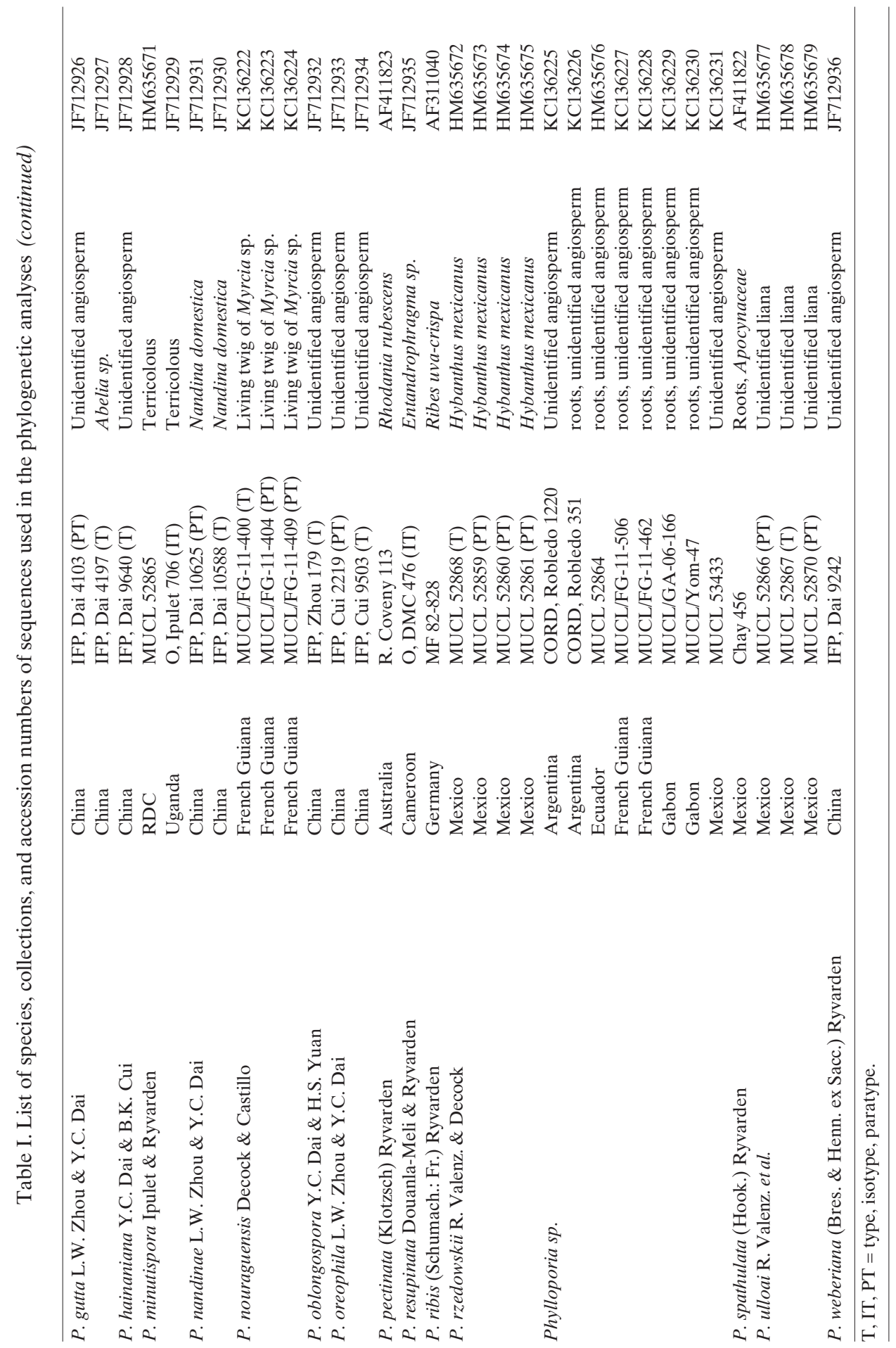


Bayesian analyses were implemented with two independent runs, each with four simultaneous independent chains for three million generations, starting from random trees, and keeping one tree every $1000^{\text {th }}$ generation. All trees sampled after convergence [average standard deviation of split frequencies $<0.01$, confirmed using Tracer v1.4 (Rambaut \& Drummond 2007)] were used to reconstruct a $50 \%$ majority-rule consensus tree (BC) and to estimate posterior probabilities. The posterior probability (BPP) of each node was estimated based on the frequency at which the node was resolved among the sampled trees with the consensus option of $50 \%$ majority-rule (Simmons et al. 2004). Clades with BPP above 0.95 were considered strongly supported by the data.

Maximum likelihood (ML) searches conducted with RAxML involved 1000 replicates under the GTRGAMMAI model, with all model parameters estimated by the program. The tree with the best likelihood value served as the starting tree for the Bayesian analyses. In addition 1000 rapid bootstrap (ML BS) replicates were run with the same GTRGAMMAI model. Clades with maximum likelihood bootstrap values of $85 \%$ or greater were considered to be significantly supported.

For MP analyses, gaps were treated as missing. The most parsimonious trees (MPT) for each data set were identified using heuristic searches with 1000 random addition sequences, further evaluated by bootstrap analysis, retaining clades compatible with the $50 \%$ majority-rule in the bootstrap consensus tree. Analysis conditions were tree bisection addition branch swapping, starting tree obtained via stepwise addition, steepest descent not in effect, MulTrees effective. Clades with bootstrap support value (BS) above $85 \%$ were considered strongly supported by the data

\section{RESULTS}

LSU analysis. - Within Phylloporia, the length of the LSU fragment ranged from 866 to 884 bps. Thirty four characters judged too ambiguous to be aligned were excluded from further analysis. The final DNA sequence alignment of the 65 sequences resulted in 904 positions of which 335 were variable and 256 parsimony informative. Using the Akaike information criterion of MrModeltest 2.3 (Posada and Crandall 1998), the best-fit model for the nucLSU data set was $G T R+I+G$ with unequal base frequencies $(A=0.2337, C=0.1974$, $\mathrm{G}=0.3281, \mathrm{~T}=0.2409$ ), a gamma distribution shape parameter of 0.4500 , and a proportion of invariable sites of 0.3690 .

The MP analysis produced 4 most parsimonious trees (1195 steps, consistency index (CI) 0.362, retention index (RI) 0.629 and rescaled consistency index (RC) 0.228). The two Bayesian runs converged to stable likelihood values after 1.795.000 generations and 8205 stationary trees from each analysis were used to compute a $50 \%$ majority rule consensus tree in PAUP* and to calculate posterior probabilities. In the ML searches with RAxML, the nuc-LSU alignment had 364 distinct patterns with a proportion of gaps and undetermined characters of $5.11 \%$.

The strict consensus of the 4 most parsimonious trees were mostly identical to the $\mathrm{BC}$ tree and to the optimal ML tree (tree score of $-\ln \mathrm{L}=-6772.914435$ ). The optimal ML tree is represented in Fig. 1. 


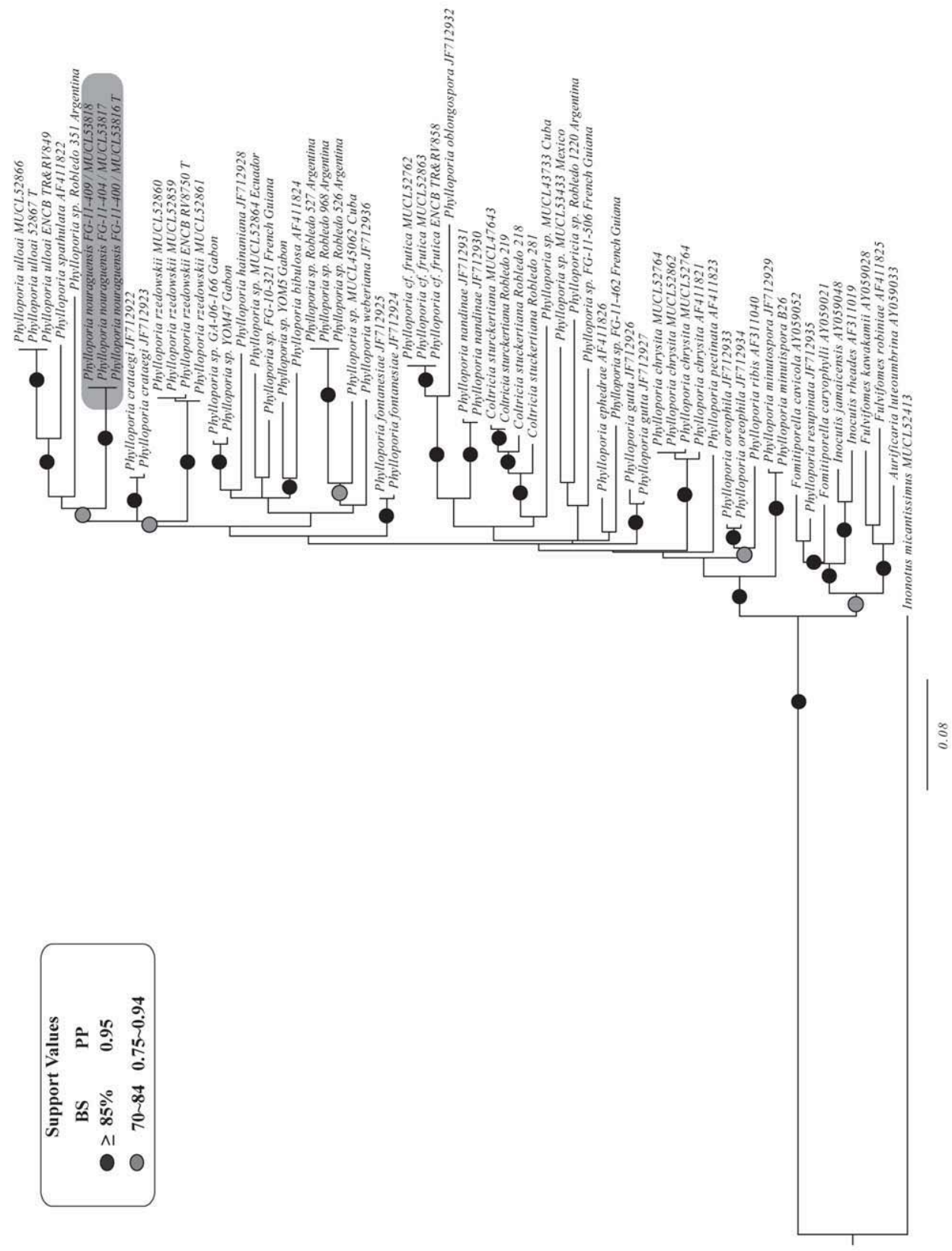

Fig. 1. Phylogenetic relationships of Phylloporia species inferred from nucLSU rDNA sequences. The maximum likelihood tree was rooted with Inonotus micantissimus MUCL52413. Black dots on branches represent BPP greater than 0.95 and ML/BS greater than $85 \%$; grey dots on branches denote BPP greater than $75 \%$ and ML/BS grater than $65 \%$. 
Phylloporia nouraguensis, an undescribed species on Myrtaceae from French Guiana 21

The topologies of the trees regarding the recovery and the relative positions of the poroid Hymenochaetales generic entities considered were identical in all the phylogenetic inferences, in accordance with previous results (Valenzuela et al. 2011). The Phylloporia clade is very well supported (BS 98\% / BPP 1.0 / ML BS $100 \%$ ). However, in our analysis, P. resupinata nests outside the Phylloporia clade, and is kin to some Fomitiporella species, questioning its generic placement.

Our phylogenetic inferences recovered our French Guiana collections FG-11-400, FG-11-404, and FG-11-409 as a distinct, well-supported (BS 100\% / BPP 1.0), monophyletic and terminal clade (Fig. 1). This clade is unequivocally placed within the Phylloporia lineage, in the vicinity of the $P$. ulloai, P. rzedowskii, P. spathulata, and P. crataegi species/clades (Zhou and Dai 2012). An unidentified collection from Argentina (Phylloporia sp., Robledo 351) is also related. These 5 species form a moderately supported sub-clade within the Phylloporia lineage (Fig. 1).

Subsequent morphological examinations of the various collections revealed combinations of morphological features which would define a morphotype. The main features that differentiate these collections from other species are the thin, tiny basidiomes, small pores, and the basidiospores shape and size. The ecological features viz. a growth on small living twigs of Myrcia sp. (Myrtaceae), the basidiomata emerging from their apices, also could characterize this species.

We therefore concluded that they represent a distinct species, described and illustrated below as Phylloporia nouraguensis.

\section{TAXONOMY}

Phylloporia nouraguensis Decock \& Castillo sp. nov.

Figs 2-4

Mycobank: MB801759

Etymology: This species is named after the locality, the Nouragues inselberg within the homonymous Nouragues Natural Reserve.

Basidiomata annua, pileata, sessilia, plerumque amplectentia, 3-8 $\mathrm{mm}$ longa, 3-12 mm lata, usque ad $1.2 \mathrm{~mm}$ crassa; pileus plerumque cinnamomeus deinde ferruginosus, leviter spongiosus, concentricus, hirsutus deinde agglutinatus et glaber in vetere; pori circulares, $8-9$ per mm, linea nigra delicata inter tomentum et contextum praediti; tomentum spongiosum; contextus densus; systema hypharum dimiticum; hyphae generatoriae afibulatae, hyalinae ad pallido-luteae; hyphae skeletales flavo-brunneae, crassitunicatae, aseptatae; basidiosporae 2.8-3.5 ×2.0-3.0 $\mu \mathrm{m}$, ellipsoideae ad obovoideas, pallido-luteae, nonamyloidae, leviter crassitunicatae; basidiomata ad ramunculos apicales viventes Myrciae sp. (Myrtaceae) crescentia.

Basidiome annual, pileate; pileus solitary, sessile, amplectens and broadly attached to discoid (button-like) and attached by a small vertex, semicircular to circular in outline, applanate (plane) to slightly convex in section, projecting 3-8 $\mathrm{mm}, 3-12 \mathrm{~mm}$ wide, up to $1.2 \mathrm{~mm}$ thick, with a corky consistency when fresh; pileus surface concentrically hirsute to slightly scrupose, with alternate zones of flattened hyphae, free or in bundles, and of hyphae abruptly bent upward, forming hirsute to slightly scrupose rows; on aging (and weathering) the hyphal bundles start agglutinating from the base and, progressively, the pileus surface becomes almost glabrous, or so when old; overall pileus surface grayish orange, cinnamon brown 

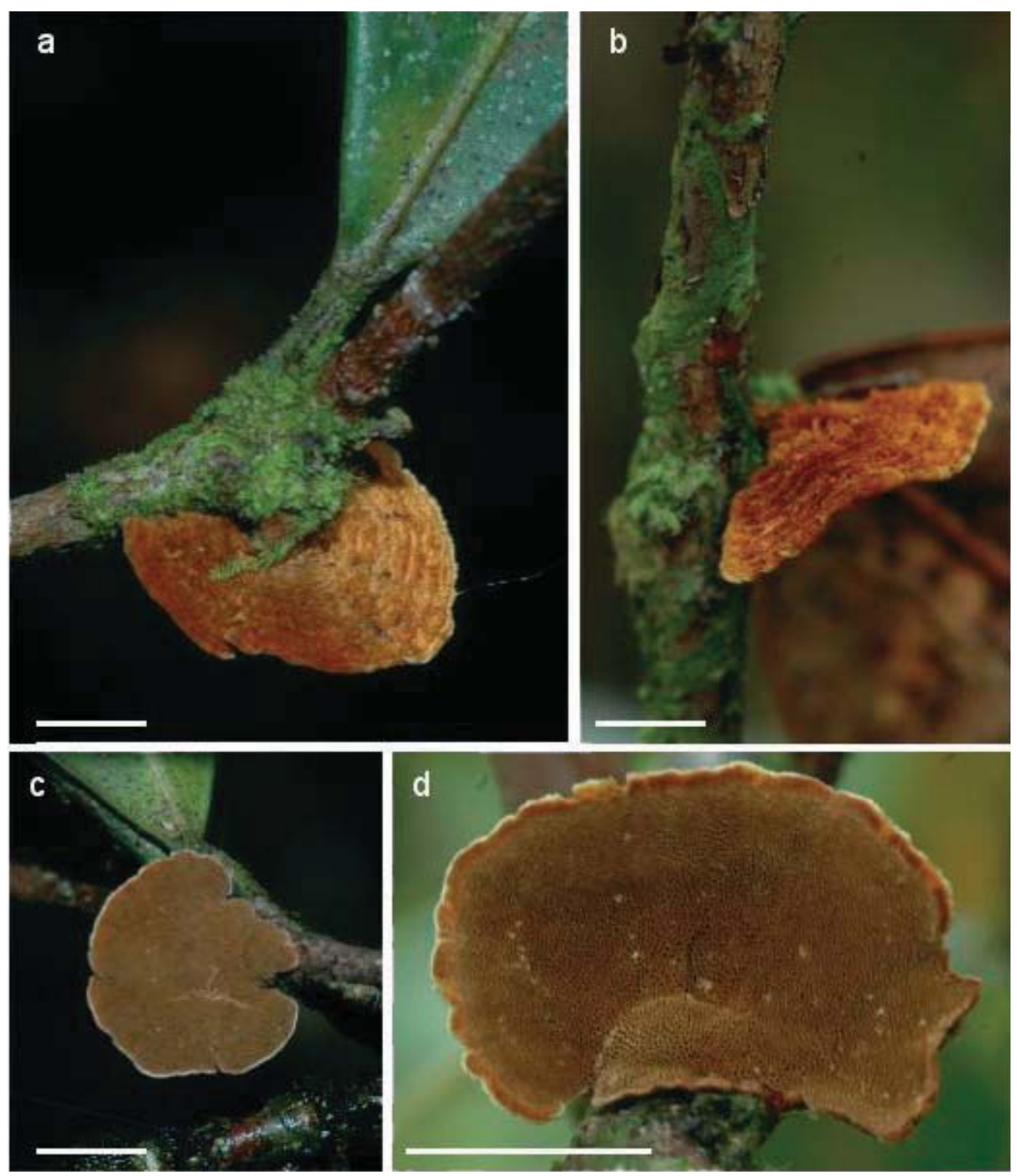

Fig. 2. a, d: Basidiomata in situ of Phylloporia nouraguensis MUCL 53816. a, b: pileus, upper surface (scale bar $=5 \mathrm{~mm}$ ); c, d: pore surface. Scale bar $=5 \mathrm{~mm}$.

[6D(6-7)], or rusty brown (6F7) when fresh and growing, the concentric rows occasionally darker, the marginal areas paler, grayish orange; on aging and when glabrous, the all pileus turning rusty brown (6F7); margin thin, sterile, white, grayish white; pore surface brownish orange to light brown [5C(4-5), golden blonde, topaz, $6 \mathrm{D}(5-6)$, cinnamon to sunburn] when fresh and growing, brown when dried [6E(7-8), rusty brown]; pores 8-9/ mm, (75-) 105-110 mm diam (ave = $87 \mu \mathrm{m})$, mostly rounded, rarely radially elongated; dissepiments smooth, entire, $25-50 \mu \mathrm{m}$ thick $($ ave $=35 \mu \mathrm{m})$; context duplex, with a thin black line separating an 


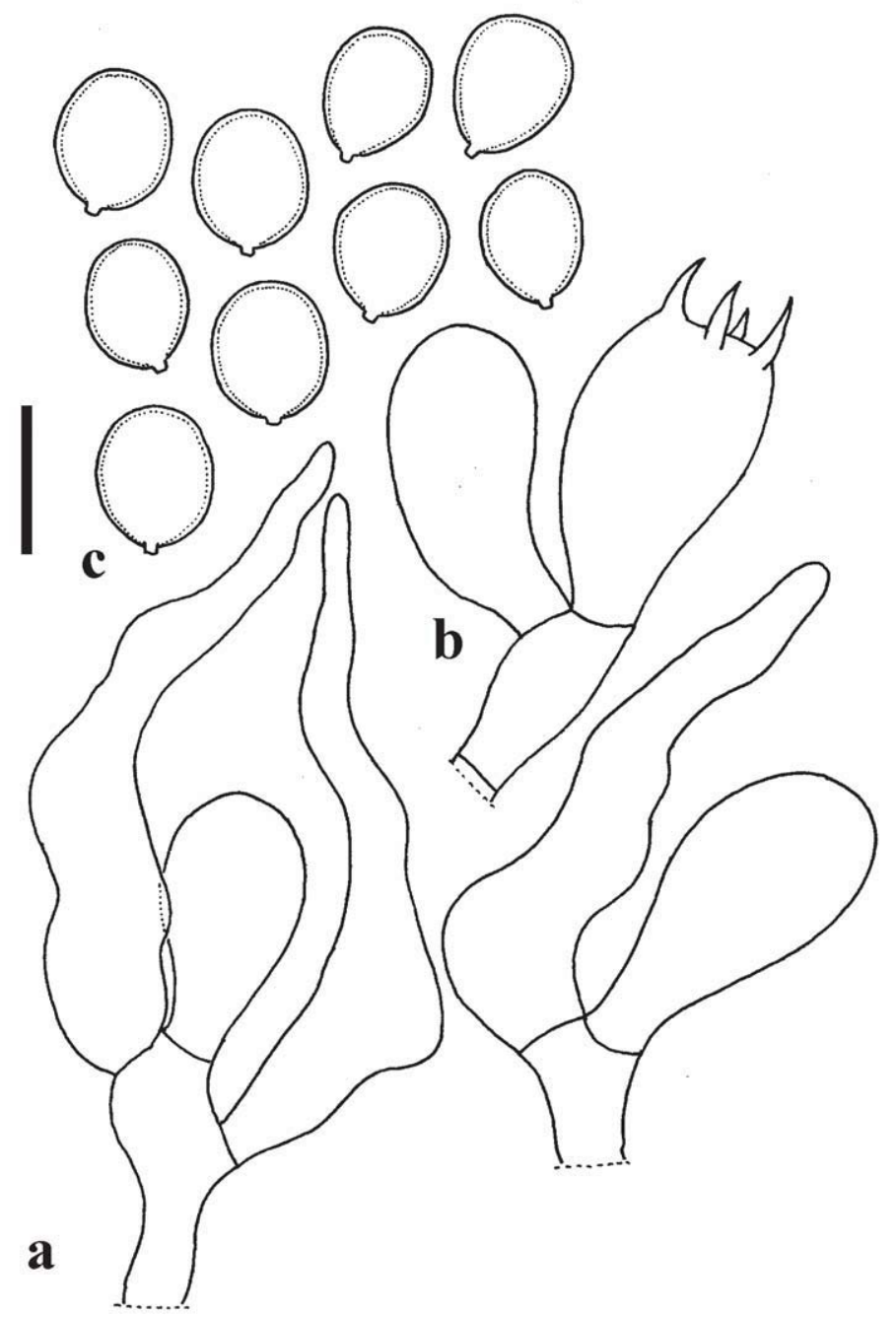

Fig. 3. a, c: Microscopic features of Phylloporia nouraguensis, from MUCL 53816. a: cystidioles / basidioles; b: basidioles / basidia; c: basidiospores. Scale bar $=5 \mu \mathrm{m}$.

upper loose tomentum and a lower denser context, more obvious near the base; upper tomentum soft and spongy, up to $0.4 \mathrm{~mm}$ thick at the base, light brown to cinnamon brown [6D(6-7), cinnamon brown], darker on aging, cocoa brown; lower context denser, up to $0.75 \mathrm{~mm}$ thick at the base, very thin (down to $0.1 \mathrm{~mm}$ ) to the margin, concolorous with the upper layer; tube layer up to $0.5 \mathrm{~mm}$ deep, yellow brown to light brown $[6 \mathrm{D}(6)]$.

Hyphal system, dimitic; generative hyphae simple septate, thin- to thick-walled (but lumen wide open), sparingly branched, hyaline to pale golden yellow, darker in $\mathrm{KOH}, 2.5-3.0(-3.5) \mu \mathrm{m}$ diam; in the tomentum, hyphae mostly parallel, unbranched, thick-walled, 3.0-5.0 $\mu \mathrm{m}$ diam, occasionally with crystals embedded; in the lower context skeletal hyphae sub-parallel, yellow to brownish, 


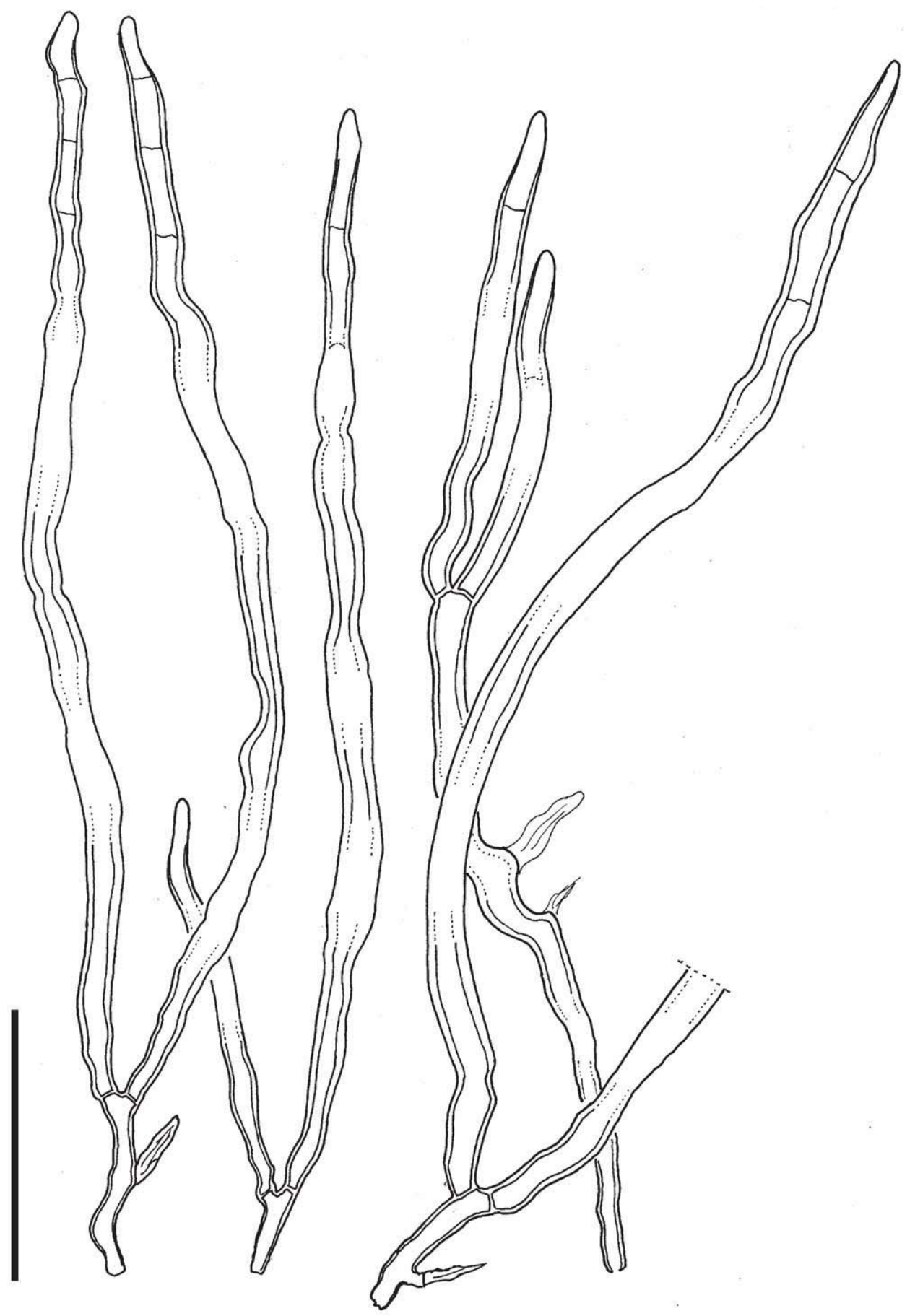

Fig. 4. Microscopic features of Phylloporia nouraguensis, from MUCL 53816. Vegetative hyphae from the hymenophoral trama, MUCL 53816. Scale bar $=20 \mu \mathrm{m}$. 
darker, reddish brown in alkali, arising from a generative hyphae, with a basal septa, of limited growth, measured up to $200 \mu \mathrm{m}$ long, 3.0-4.5 $\mu \mathrm{m}$ diam, progressively thickto very thick-walled, ending thin-walled, mostly aseptate throughout, or with (multiple) secondary septa, especially near the tips; in the hymenophoral trama skeletal hyphae with sub-parallel orientation, yellow to brownish, darker brown in $\mathrm{KOH}$, arising from a generative hyphae, with a basal septa, of limited growth, measured up to $80 \mu \mathrm{m}$ long, 2.5-3.0 (-3.5) $\mu \mathrm{m}$ wide, thick- to very thick-walled, the tips thin- to slightly thick-walled, aseptate but with (multiple) secondary septa, especially near the tips, occasionally with local constrictions.

Hymenium: cystidioles few, fusoid to lageniform, thin-walled; basidioles 8.0-10.0 $\times$ 5.0-6.5 $\mu \mathrm{m}$, hyaline in $\mathrm{KOH}$, slightly pyriform; basidia $10.0-12.5 \times 5.5-6.5 \mu \mathrm{m}$, barrel-shaped to slightly pyriform, with 4 sterigmata; basidiospores broadly ellipsoid to obovoid, subhyaline pale yellow, darkening in alkali, slightly thick-walled, smooth, without reaction in Melzer's reagent, (2.8-) 3.0-3.5 × (2.0-) 2.5-2.8 (-3.0) $\mu \mathrm{m} \mathrm{Q}=(1.12)-1.17-1.4,\left(\right.$ ave $=3.3 \times 2.6 \mu \mathrm{m}$, ave $\left._{\mathrm{Q}}=1.28\right)$.

Substrates: known so far only growing on small, living twigs of Myrcia sp. (Myrcia cf. guianensis, Myrtaceae), with basidiomes emerging just before or at the attachment points of the opposite leaves. Basidiomes also were observed, occasionally, on dead twigs.

Distribution: so far known from the type locality, in the Nouragues inselberg low forest ecosystem.

Holotype: FRENCH GUIANA: Municipality of Regina, Nouragues Natural Reserve, CNRS "inselberg" research station, track (layon) C.T.I., in the "low forest" ecosystem, at the so-called Inselberg "terrasses", approx. 04 $05.5^{\prime} \mathrm{N}$, $52^{\circ} 40.6^{\prime} \mathrm{W}$, elev. 130-180 m, on living (and dead), apical, attached twigs, Myrcia sp. (M. cf. guianensis, Myrtaceae), 29 Jun 2011, C. Decock, FG-11-400 (in herbarium MUCL 53816, Holotype; Isotype at NY).

Additional materials examined: ibid. 29 Jun 2011, C. Decock, FG-11-399, FG-11-404, FG-11-409 (respectively MUCL 53815, MUCL 53817, and MUCL 53818); ibid., 03 Jul 2012, C. Decock and G. Castillo, FG-12-560, FG-12-561 (respectively, MUCL 54461 \& MUCL 54462).

\section{DISCUSSION}

The pileate basidiomes with a duplex context, a black line separating an upper loose tomentum from a lower, denser context, a dimitic hyphal system, small, thick-walled, pale yellowish basidiospores, and the growth on living twigs point toward Phylloporia. In a phylogenetic perspective (Fig. 1), this species nests within the Phylloporia clade sensu Valenzuela et al. (2011).

Phylloporia nouraguensis is characterized by the combination of tiny, thin, mostly amplectens basidiomes, small pores $(8-9 / \mathrm{mm})$, and broadly ellipsoid to obovoid basidiospores averaging $3.3 \times 2.6 \mu \mathrm{m}$. The hyphal system could be considered as dimitic, both in the lower context and the hymenophoral trama. Skeletal hyphae originate from generative hyphae, and are of a limited growth, what is especially obvious in the hymenophoral trama. They are mostly aseptate throughout, although (multiple) secondary septa occur, more frequently near their apices. 
The ecological parameters may characterize also the species. Phylloporia nouraguensis was found growing locally (exclusively to date) on a species of Myrcia (possibly M. guianensis, Myrtaceae), developing solitary basidiomata at the attachment point of opposite leaves, near the apices of living (more rarely) dead, small ( $<5 \mathrm{~mm}$ diam) twigs. The species might be (locally) host specific; it was not observed on other local plants but, because of its small size and habitat, it could have been overlooked on taller plants.

The pileus habit and the ecology of $P$. nouraguensis call to mind $P$. rzedowskii (Valenzuela et al. 2011), a related, neotropical species known to date only from Mexico. Phylloporia nouraguensis differs from P. rzedowskii in having

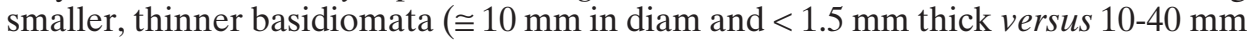
diam, up to $12 \mathrm{~mm}$ thick), smaller pores (8-9 versus $2-3 / \mathrm{mm}$ ), and smaller basidiospores $(3.0-3.5 \times 2.5-2.8 \mu \mathrm{m}$ versus $4.2-6.0 \times 2.5-3.2 \mu \mathrm{m})$.

Phylloporia nouraguensis also could be compared to P. frutica; both species have comparable (amplectens) basidiome habit. Phylloporia frutica has much larger pores, however $(2 \times 4$ per mm, Ryvarden 2004, Wagner and Ryvarden 2002).

At the Nouragues Natural Reserve, Myrcia spp. are found in the so-called "low forest" covering the upper slopes of the Nouragues inselberg, a granitic dome-like outcrop, culminating at $430 \mathrm{~m}$. This "low forest" forms a transition zone between the low land, tall-tree rainforest and the inselberg, summital, open savanna-rock botanical association. It is botanically dominated by Myrtaceae, in terms of relative diversity and abundance (Larpin 2001). The local climatic conditions are more contrasted than the surrounding lowland, tall tree rainforest, with ampler daily and seasonal fluctuations of temperature and relative humidity (Larpin 2001).

In French Guiana, Myrcia spp. are also widely distributed in open savannah and coastline ecosystems. In South America, Myrcia spp. and M. guianensis are widespread. Phylloporia nouraguensis might be searched for in these areas where Myrcia spp., M. guianensis, or perhaps other bushy Myrtaceae occur. Because of its small basidiomata and substrate specificity (apices of narrow living twigs), it might be easily overlooked.

Our phylogenetic inferences evidenced also several clades representing unnamed "species", all characterized by having stipitate basidiomes. They originate from Argentina (Phylloporia sp. Robledo 351), French Guiana (Phylloporia sp. FG-11-462, Phylloporia sp. FG-11-506), Ecuador (Phylloporia sp. MUCL 52864), and Gabon (Phylloporia sp. GA-06-166/YOM-47). They are distantly related to the other species with stipitate basidiomes for which DNA is available, viz. P. spathulata (Wagner and Ryvarden 2002) and P. minutispora (Valenzuela et al. 2011). DNA data from the third described species having stipitate basidiomes, $P$. verae-crucis, is unavailable for the time being.

Several specimens from Argentina, representing a single morphospecies tentatively named Coltricia stuckertiana but obviously belonging to Phylloporia, form also a monophyletic clade representing an additional Neotropical species with stipitate basidiomes.

A handful of Phylloporia species with stipitate basidiomes could thus emerge, especially in South America. However, additional collections would be necessary to describe carefully these species and their ecology. Furthermore, given the list of synonyms of $P$. spathulata (http://www.indexfungorum.org/Names/ Names.asp; Ryvarden 1991), of which 4 are based on type originating from the Neotropics, a name for some of these species might already exist. Type studies are still necessary. This will be dealt with in a forthcoming publication. 
Phylloporia nouraguensis, an undescribed species on Myrtaceae from French Guiana 27

Acknowledgment. Cony Decock and Gabriel Castillo gratefully acknowledge the financial support received from the FNRS / FRFC (convention FRFC 2.4544.10) that allowed fieldwork in French Guiana. Cony Decock also gratefully acknowledges the financial support received from the Belgian State - Belgian Federal Science Policy (contract BCCM C3/10/003). Mario Amalfi acknowledges the financial support received from the Université catholique de Louvain through a Fonds Special de la Recherche scholarship. Thanks are extended also to Stéphanie Huret and Céline Bivort for their help with the sequencing program. Cony Decock and Gabriel Castillo also thank Dr. Anne Corval, Director of the CNRS French Guiana, for granting authorization and facilities for field research at the Inselberg CNRS research station, and the CNRS staff members for their invaluable help in Cayenne and during field work (namely, Mrs Dorothée Deslignes, and Mr. Philippe Gaucher, Patrick Châtelet, Gilles Peroz, and Wemo Betian).

\section{REFERENCES}

CASTRESANA J., 2000. - Selection of conserved blocks from multiple alignments for their use in phylogenetic analysis. Molecular Biology and Evolution 17: 540-552.

CUI B.-K., YUAN H.-S. \& DAI Y.-C., 2010 - Two new species of Phylloporia (Basidiomycota, Hymenochaetaceae) from China. Mycotaxon 113: 171-178.

DECOCK C., HERRERA-FIGUEROA S., ROBLEDO G. \& CASTILLO G., 2007 - Fomitiporia punctata (Basidiomycota, Hymenochaetales) and its presumed taxonomic synonyms in America: taxonomy and phylogeny of some species from tropical/subtropical areas. Mycologia 99:733-752.

HUELSENBECK J.P. \& RONQUIST F., 2001 - MRBAYES: Bayesian inference of phylogeny. Bioinformatics 17: 754-755.

KORNERUP A.J. \& WANSCHER H., 1981 - Methuen Handbook of Colour. $3^{\text {e }}$ Ed. Methuen. London.

LARPIN D., 2001 - The low forest (Nouragues inselberg). In BONDERS (ed.), Nouragues. Dynamics and plant-animal interactions in a neotropical rainforest, Kluwer Academic Press, The Netherlands: pp. 47-63.

LARSSON K.-H., PARMASTO E., FISCHER M., LANGER E., NAKASONE K.K. \& REDHEAD S.A., 2006 - Hymenochaetales: A molecular phylogeny for the hymenochaetoid clade. Mycologia 98: 926-936.

POSADA D. \& CRANDALL K.A., 1998 - Modeltest: testing the model of DNA substitution. Bioinformatics 14: 817-818

RAMBAUT A. \& DRUMMOND A.J., 2007 - Tracer v1.4, [http://beast.bio.ed.ac.uk/Tracer]

RYVARDEN L., 1991 - Genera of Polypores: Nomenclature and taxonomy. Synopsis Fungorum 5: Oslo, Fungiflora.

RYVARDEN L., 2004 - Neotropical polypores 1. Synopsis Fungorum 19. Oslo, Fungiflora.

SIMMONS M.P., PICKETT K.M. \& MIYA M., 2004 - How meaningful are Bayesian support values? Molecular Biology and Evolution 21: 188-199.

STAMATAKIS A., HOOVER P. \& ROUGEMONT J., 2008 - A rapid bootstrap algorithm for the RAxML Web-Servers. Systematic Biology 75: 758-771.

SWOFFORD D.L., 2003 - PAUP*: phylogenetic analysis using parsimony (*and other methods). Version 4.0b10. Sunderland, Massachusetts: Sinauer Associates Inc.

THIERS B. [continuously updated] - Index Herbariorum: A global directory of public herbaria and associated staff. New York Botanical Garden's Virtual Herbarium. http:// sweetgum.nybg.org/ih/.

THOMPSON J.D., GIBSON T.J., PLEWNIAK F., JEANMOUGIN F. \& HIGGINS D.G., 1997 The CLUSTAL_X windows interface: flexible strategies for multiple sequence alignment aided by quality analysis tools. Nucleic Acids Research 25: 4876-4882.

VALENZUELA R., RAYMUNDO T., CIFUENTES J., CASTILLO G., AMALFI M. \& DECOCK C., 2011 - Two undescribed species of Phylloporia from Mexico based on morphological and phylogenetic evidence. Mycological Progress 10: 341-349.

WAGNER T. \& RYVARDEN L., 2002 - Phylogeny and taxonomy of the genus Phylloporia (Hymenochaetales). Mycological Progress 1: 105-116.

ZHOU L.-W. \& DAI Y.-C., 2012 - Phylogeny and taxonomy of Phylloporia (Hymenochaetales): new species and a worldwide key to the genus. Mycologia 104: 211-222. 
